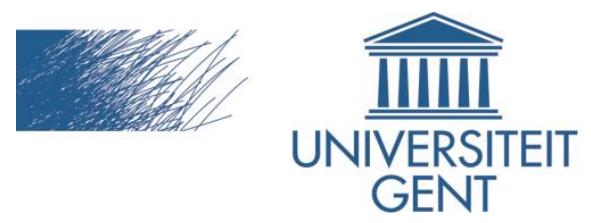

biblio.ugent.be

The UGent Institutional Repository is the electronic archiving and dissemination platform for all UGent research publications. Ghent University has implemented a mandate stipulating that all academic publications of UGent researchers should be deposited and archived in this repository. Except for items where current copyright restrictions apply, these papers are available in Open Access.

This item is the archived PEER-REVIEWED AUTHOR-VERSION of:

Title: What makes long crime trips worth undertaking? Balancing the costs and benefits in burglars' journey to cirme

Authors: Vandeviver, C., Van Daele, S. \& Vander Beken, T.

In: British Journal of Criminology, doi: 10.1093/bjc/azu078

Link to the article:

http://bjc.oxfordjournals.org/cgi/content/abstract/azu078?ijkey=7opQ1Bm039z7kzK\&keyty pe $=$ ref

To refer to or to cite this work, please use the citation to the published version:

Vandeviver, C., Van Daele, S., \& Vander Beken, T. (2014). What Makes Long Crime Trips Worth Undertaking? Balancing the Costs and Benefits in Burglars' Journey to Crime. British Journal of Criminology. doi: 10.1093/bjc/azu078 


\section{What makes long crime trips worth undertaking? Balancing costs and benefits in burglars' journey to crime}

The choices and decisions underlying burglary behaviour and shaping the journey to crime are usually interpreted using the rational choice framework (Elffers, 2004; Lu, 2003, p. 424). This framework propagates the view that these decisions are governed by a process of profit maximization and effort minimization (Pettiway, 1982; Van Koppen \& Jansen, 1998) and that burglars select targets using a spatially structured, hierarchical, sequential selection process (Bernasco \& Nieuwbeerta, 2005; Brantingham \& Brantingham, 1984) - burglars initially select a suitable area and then gradually narrow down their selection until they have identified the house they intend to burgle. Throughout this selection process, burglars balance the costs and benefits of their choice. Costs include aspects such as the time and effort it takes to travel to the area, and the risks associated with criminal movement. Benefits include a range of financial and psychological rewards obtained through successfully completing a burglary. General environmental characteristics play an important role throughout this selection and balancing process (Bennett \& Wright, 1984b; Brantingham \& Jeffery, 1981). Since burglars rely on general environmental characteristics to select target areas, we can also expect them to rely on these environmental characteristics when making an initial assessment of costs and benefits.

The majority of journey-to-crime studies conclude that travel associated with crime is limited and mostly local in nature (Mclver, 1981; Wiles \& Costello, 2000). Given that a balancing of costs and benefits shapes this behaviour and that travelling greater distances typically implies higher costs, this conclusion is understandable. Interestingly, a number of journey-to-crime studies found offender travel to be more widespread and long crime trips more common than typically reported in journeyto-crime studies (e.g. Gabor \& Gottheil, 1984; Morselli \& Royer, 2008; Polisenska, 2008; Rattner \& Portnov, 2007; Van Koppen \& Jansen, 1998). These findings spawned research on long crime trips and gave rise to new research questions, such as why offenders undertake longer crime trips, and what makes the incremental costs of long crime trips worthwhile. This paper focuses particularly on elements at the environmental level that favour the incremental costs of long crime trips, and explains how longer crime trips and their increased travel costs can be reconciled with the rational choice framework underlying journey-to-crime studies.

This paper reports on the outcome of a quantitative study carried out in a large, heavily urbanized geographic area that explored the costs and benefits that a burglar considers when deciding upon a burglary target. It treats distance as one of the major costs in the burglary target selection process and uses community characteristics to gain insight into how the anticipation of particular benefits favours the incremental costs of long crime trips. In particular, it applies negative binomial regression to model the cost of distance as a function of environmental characteristics at the community level. The broader goal of this paper is to further the understanding of the decision-making process underlying long crime trips and how such crime trips can be reconciled with the dominant rational choice framework.

The paper is structured as follows. First, previous journey-to-crime research is reviewed in order to identify gaps in the current knowledge of the journey to crime in general and long crime trips in particular. Second, we present our data and method, negative binomial regression analysis. This method is then applied to crime trips associated with residential burglaries recorded and cleared by 
local police forces in East and West Flanders, Belgium. The paper concludes with a discussion of the main results and their implications for journey-to-crime research and our understanding of long crime trips.

\section{Rational choice and the long journey to crime}

Results from quantitative and qualitative studies into burglars and burglary (e.g. Bennett \& Wright, 1984a; Bernasco \& Luykx, 2003; Nee \& Taylor, 1988) have resulted in widespread acceptance that burglary behaviour is based on a rational decision-making process (Cornish \& Clarke, 2008, pp. 40-41; Nee \& Meenaghan, 2006, p. 935). While this does not mean that burglars explicitly and elaborately balance potential profits and efforts while attempting to satisfy their needs (Canter \& Youngs, 2008, p. 14), it does imply that they exert some influence over the choice of location - the offence location is not selected randomly but is instead the consequence of a bounded decision-making strategy. We therefore assume that burglars' behaviour is characterized by purpose and logic, and consequently that offender mobility and the patterns that underlie it are a worthwhile subject of study (Bernasco \& Block, 2009). Burglars' journey to crime is a corollary of this purposeful and rational behaviour.

Rational choice theory is the preferred framework for interpreting results from journey-to-crime studies (Elffers, 2004; Lu, 2003, p. 424). From within this framework, it is argued that the decisions related to burglary target selection and that shape the journey to crime are governed by effort minimization and profit maximization (Pettiway, 1982; Van Koppen \& Jansen, 1998). When the 'costs' increase because burglars travel further, the profits are expected to increase too, effectively balancing out the increased costs. Moreover, the principle of least effort (Zipf, 1949) states that, all other things being equal, individuals will make as little effort as possible to achieve their goal. In other words, burglars aim to maximize their expected profits while keeping the anticipated efforts to a minimum by selecting easy and profitable targets close to their home. A corollary of this decisionmaking strategy is that crime trips tend to be short - a finding consistently observed in journey-tocrime research, regardless of the applied methodology and across different study regions (Bernasco, 2006; Costello \& Wiles, 2001; Gabor \& Gottheil, 1984; Pyle, Hanten, Williams, Pearson \& Doyle, 1974; Snook, 2004; White, 1932). However, a number of studies have examined offender mobility within a larger geographic region and found that many offenders are highly mobile and are willing to travel considerable distances before committing their offences (e.g. Gabor \& Gottheil, 1984; Morselli \& Royer, 2008; Rattner \& Portnov, 2007; Van Koppen \& Jansen, 1998; Wiles \& Costello, 2000). For instance, Polisenska $(2008$, p. 56) interviewed incarcerated burglars from all regions of the Czech Republic who had offended in different regions and cities. The majority indicated that they did not offend close to their home. Instead, they travelled as far as possible away from their home area in order to commit a crime, with some travelling up to $150 \mathrm{~km}$ to burgle a house.

Travelling longer distances intuitively seems at odds with the underlying rational choice framework (Rengert, Piquero \& Jones, 1999, p. 429) since it takes more time and money, and requires more effort to become familiar with distant target areas (Brantingham \& Brantingham, 1984). Carrying out burglaries closer to home would seem to be a more sensible option, because the costs tend to be lower. Surprisingly, the rational choice framework is also helpful in highlighting the usefulness of longer crime trips by pointing out that there might be good incentives to undertake them (Felson, 2006, p. 265; Morselli \& Royer, 2008, p. 6; Van Koppen \& Jansen, 1998, p. 231). 
Incentives to travel further can take many forms. Since burglars are primarily driven by monetary gain (Bennett \& Wright, 1984a; Maguire \& Bennett, 1982; Rengert \& Wasilchick, 1985), higher financial profits unsurprisingly appear to be one of the major incentives. A number of studies have established a positive relationship between the distance travelled and the profits gained from a crime trip (Baldwin \& Bottoms, 1976; Gabor \& Gottheil, 1984; Pettiway, 1982; Snook, 2004; Van Koppen \& Jansen, 1998), suggesting that travelling greater distances is more rewarding. For example, Snook (2004, pp. 61-62), relying on a quantitative design to study the behaviour of a small sample of burglars active in and around a medium-sized Canadian city, found that burglars that undertook longer crime trips obtained greater rewards than those that operated close to their home. Morselli and Royer (2008, p. 17) came to similar conclusions when they interviewed incarcerated Canadian offenders. They found that larger offending perimeters resulted in higher criminals earnings. Mobile criminals (offenders that commit offences in multiple cities) reported earnings up to 23 times greater than non-mobile criminals. Another incentive to travel to areas that are further away could be the absence of nearby profitable targets. Cities typically have an attractive opportunity structure (Pyle et al., 1974, pp. 33-36). While burglars will not necessarily burgle a great number of houses during a single crime trip (Bernasco \& Nieuwbeerta, 2005, p. 299), travelling to a nearby city might allow them to select from an abundant and more varied supply of targets (e.g. Rattner \& Portnov, 2007).

In addition to the presence of initial incentives to travel further, mobile offenders are expected to compensate for their increased criminal commute. Felson (2006, p. 265) argues that when offenders undertake long crime trips they are likely to stay longer at their selected crime site. Van Daele and Vander Beken (2011b, p. 74) found that committing multiple offences during a single crime trip was a compensation strategy used by burglars operating from the Belgian capital. They found that $28.7 \%$ of crime trips that started within a city but ended outside it were part of a series of offences committed within eight hours of each other, while this was only the case for $6.1 \%$ of crime trips that started and ended within the same city. Moreover, committing multiple offences over a short period of time exhibited the strongest positive effect on the likelihood of structurally undertaking crime trips that end outside the home city. Other quantitative studies suggest that using an efficient means of transport might be another compensation strategy, since it allows criminals to travel greater distances more quickly (cf. inter alia Bichler, Orosco \& Schwartz, 2012; Snook, 2004; Van Koppen \& Jansen, 1998). For instance, using highways or travelling along major arterial roads compensates for the additional effort it takes to cover greater distances (Beavon, Brantingham \& Brantingham, 1994; Rossmo, 2000, p. 190; Van Daele \& Vander Beken, 2011b, p. 74). In the same vein, Snook (2004, p. 62) observed that Canadian burglars with vehicle access travelled further than those that walked or used a bicycle. In turn, burglars using a bicycle travelled further than those that walked. An additional compensation for travelling longer distances could be the attraction of areas they consider to be low risk in terms of detection. Burglars prefer to operate in areas with a reduced chance of detection and arrest (Bernasco \& Luykx, 2003; Van Daele \& Vander Beken, 2011a, p. 132). Capone and Nichols (1976) found that the longest robbery trips in Miami-Dade County targeted a chain of stores with a particular type of retail operation, resulting in a lower risk of being arrested. This preference for lowrisk areas may encourage burglars to travel further (Lu, 2003, p. 424), ostensibly raising the costs associated with their offence. However, while the travel costs increase, the chance of detection actually decreases, resulting in an overall decrease in the costs associated with the offence (cf. Mclver, 1981, p. 22). In other words, the lower chance of detection compensates for the increased travel costs. 
Results from empirical studies suggest that offenders initially experience particular incentives to travel further, and when they do they deploy additional compensation strategies to compensate for the incremental costs of increased travelling. It would be expected that offenders would need to be familiar with a target area in order to understand the potential incentives to travel further to reach it. However, based on results from offender interviews in Belgium and the Czech Republic, it appears that long crime trips are made to previously unknown areas (Polisenska, 2008, pp. 55-56; Van Daele \& Vander Beken, 2011a, pp. 131-133). This raises the question of how offenders can assess incentives and their potential advantage in advance.

The process burglars use to select their target may hold the key to this conundrum. Burglars are expected to follow a spatially structured, sequential and hierarchical decision process when selecting targets (Bernasco \& Nieuwbeerta, 2005; Brantingham \& Brantingham, 1984). This implies that they gradually narrow down their selection of a specific target, beginning with a particular community or neighbourhood they prefer to operate in and gradually increasing their focus until they have selected the particular house to burgle. In other words, before selecting their target, burglars will first select a particular town, then a neighbourhood, and finally a street. Results from a variety of studies that have applied different methodologies, including offender interviewing, discrete spatial choice analysis and experiments, suggest that general environmental characteristics play an important role throughout this target selection process (Bennett \& Wright, 1984b; Bernasco \& Nieuwbeerta, 2005; Nee, 2003; Nee \& Meenaghan, 2006; Nee \& Taylor, 1988; Taylor \& Nee, 1988). These characteristics help burglars to select a suitable target area before relying on more detailed characteristics when narrowing down their choice to a particular house. Since burglars experience certain incentives that make them travel further and rely on compensation strategies to balance increased travelling costs, the initial moment of selecting a particular target area is likely to be when they assess costs and benefits associated with the area they have chosen. Therefore, rather than focusing on the outcome of this target selection process, i.e. the actual house that is burgled, in our analysis we focus on the initial choice of a specific target area. In particular, we hypothesize that burglars rely on general environmental characteristics to assess costs and benefits, just as they rely on these environmental characteristics to select target areas. In other words, it is expected that burglars will rely on their own general knowledge and the environmental characteristics of the target area in order to assess the potential incentives of undertaking long crime trips and whether the incremental costs of travelling further can be compensated for. If this is indeed the case, a detailed analysis of the environmental context and journey-to-crime distances will advance our theoretical understanding of long crime trips (Lundrigan \& Czarnomski, 2006).

This paper introduces two advances on previous journey-to-crime studies. First, offender mobility and the journey to crime are studied within the context of a large, heavily urbanized geographic area composed of several large cities and multiple smaller towns. This approach helps to identify a broader range of crime trip distances, which is precluded by focusing on smaller geographic areas such as a single city. Moreover, a variety of criminal travelling patterns can be explored, such as the decision to remain in cities or towns to commit offences, to travel from a city to a small town (and vice versa), or to travel from one town to another. Previous journey-to-crime studies have primarily relied on data from small geographic areas, such as a single city or small urban area, to study trip lengths and offender mobility (e.g. Hesseling, 1992; Phillips, 1980; Rhodes \& Conly, 1981; Snook, 2004; White, 1932). Such studies are therefore biased towards finding short crime trips and predominantly local travelling patterns, and omitting long crime trips. A few journey-to-crime studies 
have focused on larger geographic areas (e.g. Capone \& Nichols, 1976; Gabor \& Gottheil, 1984; Smith, Bond \& Townsley, 2009; Wiles \& Costello, 2000) and found sizeable numbers of long crime trips in their crime data, but their study areas are often a single large city or metropolitan area. Focusing on a smaller geographical area prevents the identification of longer crime trips and makes it difficult to study a more diverse range of criminal travelling behaviour; therefore, the current analysis focuses on a study area that covers 6,151 square kilometres, contains 115 cities and smaller towns (including the third most populous city of Belgium) and has more than 2.5 million inhabitants.

The second innovation is the focus on how burglars balance their profits and efforts when selecting target areas, and what environmental information plays a key role in this process. It does this by focusing on a major cost in this process, the distance from the home to the crime site, as the outcome of this balancing process, and explores a selection of environmental characteristics that affect burglars' decision to target nearby or more distant areas. A few studies have examined how offenders compensate for the incremental costs of travelling to more distant targets and found that increased mobility tends to result in higher financial rewards (inter alia Morselli \& Royer, 2008; Snook, 2004; Van Koppen \& Jansen, 1998). However, these studies relied on reported financial rewards that were acquired after successfully completing an offence. This information is largely uncertain before the offence is successfully completed and can therefore not be the initial driving factor behind a burglar's decision to travel to a particular area or burgle a certain house. Instead, when considering the initial decision to commit a burglary further away from home, the focus should be on those pieces of information that can be reasonably expected to be available to the burglar at the time a decision is made. Coincidentally, an implicit decision on the crime trip distance is made at this point in time as well. A larger target area is selected before the actual house is chosen. In other words, distance to crime is primarily the result of the initial choice of a target area rather than of the house that is ultimately burgled. Burglars might have an idea of the potential profits that can be realized, but they will rarely have accurate and full information on the profits that will be made. Instead, burglars need to assess information that helps them to evaluate possible financial profits and anticipate future rewards. Environmental cues, such as whether the prospective area is wealthy or how actively the police patrol the street, can be helpful in this process and deserve further attention (Bernasco \& Luykx, 2003; Bernasco \& Nieuwbeerta, 2005; Nee \& Meenaghan, 2006). This current study aims to identify how different environmental characteristics affect burglars' decision to travel to a particular area. It hopes to provide insight into the underlying thought process of burglars that affects their decision to target certain areas, and as a corollary their decision to travel a greater or shorter distance to a burglary target.

\section{Data and methods}

\section{Data sources}

Various data sources are combined in the analysis. The primary source for this study is crime data recorded by 46 of the 48 local police forces operating in East and West Flanders, Belgium. East and West Flanders ${ }^{1}$ are two north-western provinces covering an area of 6,151 square kilometres and with a population of 2,610,798 in 2011. The study area borders France in the west and the Netherlands in the north. It has a dense road network with several important motorways, making it

\footnotetext{
${ }^{1}$ The study only focuses on the 115 municipalities of East and West Flanders that fall within the jurisdiction of any of the 46 participating local police forces.
} 
possible to reach all cities and towns in the area in less than two hours. There is an extensive and widely used rail and public transport network linking the majority of cities and towns. The study area is heavily urbanized with 28 cities, including Ghent, the third most populous city in Belgium ${ }^{2}$, and 87 smaller towns. There are also several large industrial zones and two international seaports. On average, a municipality in the study area has a surface of 45.18 square kilometres (S.D.=27.12; Min.=10.00; Max.=156.18), with a population of 21,184 inhabitants (S.D.=27,400.95; Min.=2,076; Max.=247,486) and 10,943 residential units (S.D.=14,332.79; Min.=786; Max.=110,251).

All initial police reports for cases of aggravated burglary that have been detected and resulted in the identification of at least one offender by one of the 46 local police forces for the period 2006 to 2011 inclusive were extracted from the local police databases. The burglary clearance rates data obtained from the Belgian Federal Police suggest that the local police forces operating in the study area registered a total of 25,613 burglaries (period 2009-2011) and were able to identify at least one offender for 2,813 burglaries. This corresponds to a burglary clearance rate of $10.98 \%$ for the entire study area. On average, 74.24 burglaries per year were recorded in each municipality in the study area (S.D.=174.11; Min.=2.67; Max.=1,805.33) and at least one offender was identified for 8.15 of these registered burglaries (S.D.=18.40; Min.=.00; Max.=185.67). This results in the average clearance rates reported in table 2 . For each record, the data provides information on the recording police force, the year the burglary was committed, the address of the burgled house and the number of identified suspects together with their gender, age, nationality and individual home addresses at the time of the burglary.

Prior to analysis, the data were cleaned and a number of cases were excluded from further analysis. In order to be selected, cases had to fall within the adopted time window and be committed inside the jurisdiction of the participating local police forces. Moreover, they had to involve offenders residing in the jurisdiction of any of the participating local police forces at the time of the offence and for which the legal address was available. Finally, all addresses had to be unambiguously geocodable with address level precision. These criteria and the resulting loss of information are depicted in detail in table 1. A total of 1,754 cleared burglary cases were examined. These cases correspond to 1,960 unique offenders that undertook 2,387 different crime trips.

Table 1 Selection of burglary cases

\begin{tabular}{|c|c|c|}
\hline Selection criterion & Burglaries & Burglars \\
\hline Cleared burglaries in recorded crime data & 2,372 & 2,728 \\
\hline Committed in the period 2006-2011 & 2,351 & 2,706 \\
\hline $\begin{array}{l}\text { Committed in the jurisdiction of participating } \\
\text { local police forces }\end{array}$ & 2,339 & 2,696 \\
\hline $\begin{array}{l}\text { Involving offenders residing in the } \\
\text { jurisdiction of participating local police } \\
\text { forces }\end{array}$ & 1,966 & 2,224 \\
\hline $\begin{array}{l}\text { For which legal address information was } \\
\text { available }\end{array}$ & 1,925 & 2,178 \\
\hline $\begin{array}{l}\text { Unambiguously geocodable with address } \\
\text { level precision }\end{array}$ & 1,754 & 1,960 \\
\hline
\end{tabular}

\footnotetext{
${ }^{2}$ In 2011 the first and second most populous areas in Belgium were the Brussels metropolitan area and the city of Antwerp.
} 
The recorded crime data were supplemented with publicly available socio-economic background variables at the community level from Statistics Belgium (Statbel) and burglary clearance rates from the Belgian Federal Police. To be consistent and minimize the loss of information due to missing values in the statistical analysis, a single value was used for all the environmental characteristics that were included. When the available information spans the entire time window or only part of it, the average across all available years was computed and used in the analysis (cf. Bernasco \& Luykx, 2003, pp. 988-989). When the information predated the time window, the most recently available information was used.

\section{Variables and appropriate hypotheses}

\section{Dependent variable: journey-to-crime distance}

The dependent variable is journey-to-crime distance. It is considered a proxy for the costs associated with travelling to a burglary location. Journey-to-crime distances are estimated by computing straight-line distances in metres between the Google Maps coordinates of the official offender's address (origin) and the offence location (destination). The primary unit of analysis is the individual crime trip.

Although more than one offender was involved in $29.10 \%$ of all the burglary cases $(\mathrm{N}=510)$, crime trip distances were computed for all offenders individually. Since Bernasco (2006) has shown previously that co-offenders are very similar to individual offenders in their selection of targets, we adopted this pragmatic solution to overcome the complexity of deciding on the correct starting point of the crime trip and computing the more complicated co-offending crime trip distances.

Though this paper focuses on long crime trips, the full spectrum of crime trip distances is included when estimating the regression models. Nevertheless, it is important to provide a definition of long crime trips. Similar to Wiles and Costello (2000, p. 10), long crime trips are quantitatively defined: trips that are at least $10 \mathrm{~km}$ in length are classified as 'long'.

The 2,387 burglary trips varied considerably in length, with the shortest starting and ending in the same building ( $\min .=0.00$ ) and the longest ending $128.02 \mathrm{~km}$ from the offender's home. The distribution of burglary trips was severely positively skewed, with an average trip length of $8.17 \mathrm{~km}$ (S.D.=15.05) and a median trip length of $2.57 \mathrm{~km}$. This results in the aggregate journey-to-crime distribution, which can be observed in figure 1. While the majority $(77.63 \% ; \mathrm{N}=1,853)$ of crime trips were clearly short, $22.37 \%$ ( $\mathrm{N}=534$ ) were found to be longer than $10 \mathrm{~km}$ and could be classified as long crime trips. The current sample of burglary trips therefore contains variability in crime trip length and includes a substantial number of long crime trips. 


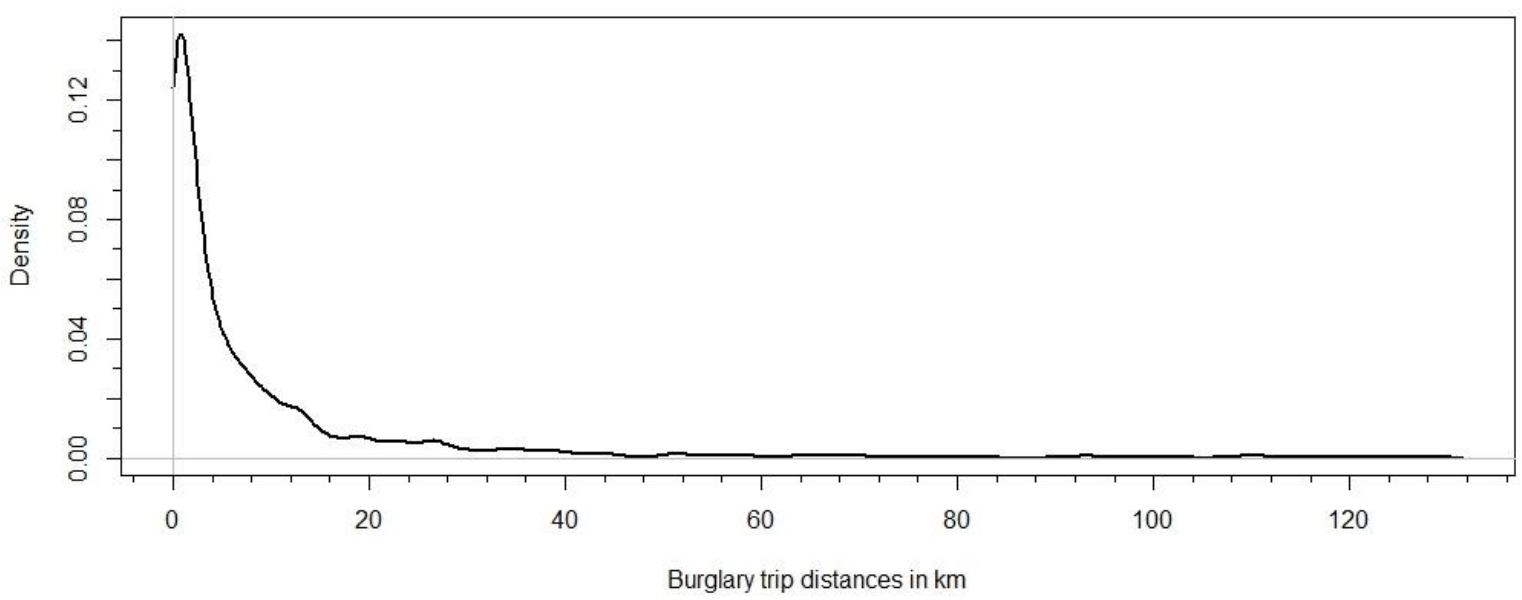

Figure 1 Kernel density estimation (see Appendix 2 for details) for aggregate distance-to-crime distribution (with a lower bound of zero)

$\underline{\text { Independent variables: community characteristics }}$

A variety of community characteristics have been included that attempt to capture incentives and compensation strategies related to the journey to crime and burglary behaviour. Previous studies established that higher monetary gains are an important incentive to increase the travel costs of a burglary, yet it is unclear whether wealthier areas are targeted or not. Therefore, we have included a measure of the wealth of target areas. We expect burglars to choose wealthier areas over poorer areas since the expected profits will be greater in affluent areas. The affluence of areas has been measured using the average sales price in EUR 10,000 for property in the area. We hypothesize that:

1. The higher the target area's average property value, the greater the likelihood will be that burglars will, ceteris paribus, travel further to carry out a burglary in that area.

Another criterion that can influence burglars' decisions to increase the costs of their burglary, i.e. to travel further, is the anticipated opportunity structure and number of opportunities present in the target area. We expect burglars to prefer areas with an abundant supply of opportunities to ones that have fewer suitable targets. The attractiveness of an area in terms of the number of opportunities it offers to burglars is measured using population density, in 100 residents per square kilometre in the target community. In particular, we hypothesize that:

2. The higher the population density of the target area, the greater the likelihood that burglars will, ceteris paribus, travel further to carry out a burglary in that area.

Third, the extent to which target areas are accessible is also a factor that could affect burglars' decisions to target a certain area or not, and thereby increase the costs of their burglary (Beavon et al., 1994). Some targets are easily accessible because they are near a motorway or major arterial road, while others are less accessible because they are located in remote or hard-to-reach areas. The accessibility of areas is measured using the road network density in kilometres of road per square kilometre in the target area and a variable that considers whether a motorway is present in the target area or not. Our hypotheses with respect to the accessibility of target areas are: 
3. Burglars are, ceteris paribus, more likely to travel further to carry out a burglary in target areas that are crossed by a motorway.

4. The higher the road network density of the target area, the greater the likelihood that burglars will, ceteris paribus, travel further to carry out a burglary in that area.

The anticipated risk of detection and chance of being arrested are also important criteria that might affect burglars' decisions to target a particular, more distant area. Areas with an unstable and noncohesive social structure are thought to be more attractive to burglars, since residents of such areas are believed to be less likely to recognize strangers and less willing to take appropriate measures when confronted with unwanted visitors and behaviour in their area (Bernasco, 2006; Bernasco \& Luykx, 2003; Bernasco \& Nieuwbeerta, 2005). Ethnic heterogeneity and residential mobility are two socioeconomic characteristics that are closely linked with a lack of social cohesion and collective efficacy in the area (Bursik \& Grasmick, 1993; Sampson \& Groves, 1989). An ethnically diverse neighbourhood and a high turnover of residents undermine the creation of social relationships between area residents and make it difficult for newcomers to integrate into the existing social structures of the area. The risk of detection and chance of arrest are measured using ethnic heterogeneity, operationalized as the percentage of non-Belgian residents in the target area, and residential mobility, computed by averaging the percentage of residents moving into a community and the percentage moving out (Bernasco, 2006, p. 148). In addition, we use an objective measure of risk (cf. Van Daele \& Vander Beken, 2011b, p. 72): the chance of being apprehended by the police. This measure is computed by dividing the number of burglaries for which at least one known offender was identified by the police, by the total number of burglaries known to the police in the target area. In particular, we hypothesize that:

5. The higher the degree of ethnic heterogeneity in the target area, the greater the likelihood that burglars will, ceteris paribus, travel further to carry out a burglary in that area.

6. The higher the degree of residential mobility in the target area, the greater the likelihood that burglars will, ceteris paribus, travel further to carry out a burglary in that area.

7. The higher the chance of arrest in the target area, the less likely it will be that burglars will, ceteris paribus, travel further to carry out a burglary in that area.

Table 2 provides descriptive statistics and the non-linear Spearman correlation matrix for these community-level variables. This table also contains a concise overview of the time span for which these variables were available and the source of the data. ${ }^{3}$ The information in the correlation matrix signals that some community characteristics are weak to moderately correlated but no community characteristics are strongly correlated, suggesting that there is no substantial overlap between any of the included community characteristics. The signs for the correlation between the wealth measure in our study (average property sales price) and the security measure (clearance rate) are especially noteworthy. This sign is not as expected. One would expect a higher degree of security in wealthier municipalities, indicated by a positive sign in the correlation matrix. However, the opposite is true and a negative sign is observed: wealthier communities tend to have a lower degree of security.

\footnotetext{
${ }^{3}$ An additional check revealed that home and target areas were very similar in terms of the community-level variables (see table 4 in Appendix 1). Moreover, the variables did not differ markedly between city-sized and town-sized municipalities (not reported here).
} 


\begin{tabular}{|c|c|c|c|c|c|c|c|}
\hline & (1) & (2) & (3) & (4) & (5) & (6) & (7) \\
\hline (1) Property sales price & 1.00 & & & & & & \\
\hline (2) Population density & $-.30^{* *}$ & 1.00 & & & & & \\
\hline (3) Motorway ${ }^{\dagger}$ & .18 & $.21^{*}$ & 1.00 & & & & \\
\hline (4) Road density & $-.23^{*}$ & $.61^{* *}$ & .03 & 1.00 & & & \\
\hline (5) Ethnic heterogeneity & -.18 & $.49^{* *}$ & .13 & $.22^{*}$ & 1.00 & & \\
\hline (6) Residential mobility & $.25^{* *}$ & -.03 & -.04 & .01 & .15 & 1.00 & \\
\hline (7) Clearance rate & $-.25^{* *}$ & $.33^{* *}$ & .13 & .12 & $.31^{* *}$ & .06 & 1.00 \\
\hline Mean & 19.62 & 4.73 & .46 & 4.52 & 2.12 & 4.90 & 10.85 \\
\hline S.D. & 5.06 & 3.16 & -- & 1.46 & 1.53 & .74 & 5.78 \\
\hline Min. & 12.59 & .53 & -- & 2.35 & .63 & 3.51 & .00 \\
\hline Max. & 52.78 & 18.4 & -- & 9.79 & 9.65 & 7.78 & 33.33 \\
\hline Period & $2006-11$ & $2006-11$ & 2005 & 2005 & $2006-11$ & 2010-11 & 2009-11 \\
\hline Source & Statbel & Statbel & Statbel & Statbel & Statbel & Statbel & Police \\
\hline
\end{tabular}

Control variables: offender characteristics

Offender characteristics were extracted from the recorded crime data and serve as control variables in the regression models. In our analysis, we controlled for the offender's age at the time of the offence and their gender. In addition, we computed a variable that measures whether an offender has burglary experience by counting the number of times the same person is mentioned in the recorded crime data for different burglary cases. Moreover, we constructed a variable that measures co-offending by verifying how many different, identified offenders are linked to a single burglary case.

The 1,960 unique burglars in the recorded crime data were on average 29.58 years old (S.D.=13.00). The youngest burglar was 6 years old and the oldest was 84 at the time of his offence. A total of $83.20 \%$ of all burglars were male. The vast majority of burglars had no experience of committing burglaries: $98.20 \%$ of all burglars appeared only once in the recorded crime data. Some $47.70 \%$ of all burglars committed their offence with one or more people.

\section{Method}

In order to estimate the effects of the selected independent variables on journey-to-crime distance, the negative binomial (Poisson-gamma mixture) regression model is employed. The negative binomial regression model is related to the simpler Poisson regression model and allows to explicitly model non-negative, skewed data such as distance-to-crime data (the distance-to-crime distribution can be observed in figure 1). Both models have some very desirable statistical properties when modelling distance-to-crime data (Hilbe, 2011, p. 30; Levine, Lord \& Park, 2010, p. 24): they will not predict negative values since their underlying distributions have a minimum of zero, and they are intrinsically right skewed, i.e. they have a long tail on the right of the distribution. The Poisson regression assumes that the variance of the model equals the mean (Hilbe, 2011), but when the data are over-dispersed this will usually result in the variance being larger than the mean (Levine et al., 2010, pp. 27-28). This is the case for the distance-to-crime variable currently under consideration: the variance is 27,730 times larger than the mean (variance $=226,524.16 \mathrm{~km}$; mean=8.17km). The negative binomial regression does not have this assumption and allows for more flexibility in 
modelling the mean and variance. It is a mixed function model that assumes that the mean follows a Poisson distribution and the variance a gamma distribution (Hilbe, 2011), hence the name Poissongamma mixture. Like other generalized linear models, the negative binomial regression model is tested with a link function, in particular the natural logarithm. This makes the interpretation of the results less straightforward than within the more familiar linear regression model, which relies on the identity link. The negative binomial regression is an exponential function that models the natural logarithm of the expected outcome on the predicted variable as a function of the predictor variables. For a unit change in the predictor variable, distance-to-crime increases exponentially by the respective regression coefficient, controlling for all other predictors in the model. Levine and Lee (2013) have previously discussed and demonstrated the appropriateness of the negative binomial regression to model highly skewed data in general and distance-to-crime data in particular.

Initially, an intercept-only model (M0) was fitted to serve as a baseline model to compare more advanced models and assess their improvement in relation to an empty model. Next, a model containing only individual characteristics (M1) was fitted, followed by a model including the community characteristics (M2).

Model fit was assessed in several ways. Since all models are nested the likelihood-ratio test can be used (cf. Hilbe, 2011, pp. 67-68). This test compares the log-likelihood of the restricted and full model and is chi-square distributed with the degrees of freedom equal to the difference in the degrees of freedom between the two compared models. In addition, both the Aikaike Information Criterion (AIC) and Bayesian Information Criterion (BIC) were used to assess improvements in model fit (Hilbe, 2011, pp. 68-75). Lower values for both information criteria indicate superior model fit. Finally, the dispersion parameter $\alpha$ gives an indication of the amount of over-dispersion present in the data and the extent to which a negative binomial model fits the data better than a simpler Poisson model. In the latter case, $\alpha$ would equal zero. This can formally be tested by computing the likelihood-ratio test of $\alpha=0$. This test compares the log-likelihood of a similar Poisson model and the negative binomial model and is chi-square distributed with the degrees of freedom equal to the difference in the degrees of freedom between the two compared models.

\section{Results}

To answer our research question, we assessed which environmental characteristics favoured undertaking long crime trips. The results of the negative binomial regression analysis are presented in table 3.

The model with individual characteristics (M1) fitted the data significantly better than the interceptonly model (M0). While the outcome of the likelihood ratio test $(\mathrm{LR}=14.46 ; \Delta \mathrm{df}=4 ; p=0.003$ ) and the smaller AIC-value for model M1 supported this conclusion, the increase in BIC suggested otherwise. With regard to the appropriateness of the negative binomial regression model, the $\alpha$-value of 3.22 suggested considerable over-dispersion and the results for the likelihood-ratio test for $\alpha=0$ confirm that a negative binomial model is appropriate $(\mathrm{LR}=37,058,548.86 ; \Delta \mathrm{df}=1 ; p<0.001)^{4}$. All in all, this model is deemed acceptable. Looking at the coefficients for model M1 displayed in table $\mathbf{3}$, we found

\footnotetext{
${ }^{4}$ Intercept-only Poisson regression model: log-likelihood $=-18,756,985.97(\mathrm{df}=2,342)$; individual variables only Poisson regression model: log-likelihood $=-18,551,178.03(\mathrm{df}=2,338)$; individual and community characteristics Poisson regression model: $\log$-likelihood $=-18,173,228.81(\mathrm{df}=2,331)$.
} 
that gender was the only factor that was significantly related to crime trip length. The effect suggests that females were more likely to undertake longer crime trips than males. No other individual characteristics were significantly associated with journey-to-crime distance.

The next model (M2) modified the previous one by combining individual and community characteristics; individual characteristics were treated as control variables only. Including community level characteristics significantly improved the model fit ( $L R=30.84 ; \Delta d f=7 ; p<0.000)$. Moreover, the AIC exhibited a decrease in size, signalling that a combination of individual and community characteristics are better at explaining variability in crime trip length than individual characteristics alone. The BIC, however, suggested otherwise. Again, the $\alpha$-value of 3.19 signalled considerable over-dispersion and the results of the likelihood-ratio test for $\alpha=0$ showed that a negative binomial model is an appropriate choice ( $L R=36,302,681.26 ; \Delta d f=1 ; p<0.001)$. Focusing on the results for model $\mathrm{M} 2$ in table 3, we find that community characteristics were more important than individual characteristics for understanding crime trip length. None of the offender characteristics were significantly associated with crime trip length. A choice of community characteristics, however, exhibited a significant association with journey-to-crime distance. In particular, the journey-to-crime distance was found to increase when burglaries were committed in communities that are crossed by a motorway, that have a dense road network and that are ethnically heterogeneous. Journey-tocrime distance decreased when burglaries were committed in densely populated areas and in communities that have a high burglary clearance rate. Population density exhibited the strongest relationship with journey-to-crime distance, as indicated by the Wald chi-square value (Wald chisquare=17.671). Although expected to be associated with journey-to-crime distance, property sales price and residential mobility were not significantly related to crime trip length.

Table 3 Estimates and model fit for negative binomial regression models

\begin{tabular}{|c|c|c|c|}
\hline & $\begin{array}{c}\text { M0 - intercept-only } \\
\text { B } \\
\text { (S.E.) }\end{array}$ & $\begin{array}{c}\text { M1 - individual } \\
\text { B } \\
\text { (S.E.) }\end{array}$ & $\begin{array}{c}\text { M2 - individual \& community } \\
\text { B } \\
\text { (S.E.) }\end{array}$ \\
\hline Constant & $\begin{array}{c}9.02^{* * *} \\
(.04)\end{array}$ & $\begin{array}{c}8.82^{\text {** }}(.12) \\
(.5)\end{array}$ & $\begin{array}{l}8.10 \\
(.33)\end{array}$ \\
\hline \multicolumn{4}{|l|}{ Individual characteristics } \\
\hline Gender: female & -- & $\begin{array}{l}.22^{*} \\
(.11)\end{array}$ & $\begin{array}{c}.21 \\
(.11)\end{array}$ \\
\hline Age & -- & $\begin{array}{c}.01 \\
(.00)\end{array}$ & $\begin{array}{l}.01 \\
(.00)\end{array}$ \\
\hline Co-offending: yes & -- & $\begin{array}{l}-.04 \\
(.08)\end{array}$ & $\begin{array}{l}-.06 \\
(.08)\end{array}$ \\
\hline Burglary experience: yes & -- & $\begin{array}{l}.32 \\
(.16)\end{array}$ & $\begin{array}{c}.25 \\
(.17)\end{array}$ \\
\hline \multicolumn{4}{|l|}{ Community characteristics } \\
\hline Property sales price & -- & -- & $\begin{array}{c}.01 \\
(.01)\end{array}$ \\
\hline Population density & -- & -- & $\begin{array}{c}-.07^{\star * *} \\
(.02)\end{array}$ \\
\hline Motorway: yes & -- & -- & $\begin{array}{l}.19^{*} \\
(.09)\end{array}$ \\
\hline Road density & -- & -- & $\begin{array}{l}.09^{*} \\
(.04)\end{array}$ \\
\hline Ethnic heterogeneity & -- & -- & $\begin{array}{l}.05^{*} \\
(.02)\end{array}$ \\
\hline Residential mobility & -- & -- & $\begin{array}{c}.10 \\
(.05)\end{array}$ \\
\hline Clearance rate & -- & -- & $\begin{array}{l}-.02^{*} \\
(.01)\end{array}$ \\
\hline
\end{tabular}




$\begin{array}{lccc}\mathbf{N} & 2,343 & 2,343 & 2,343 \\ \text { Df } & 2,341 & 2,337 & 2,330 \\ \text { Deviance } & 3,031.80 & 3,030.34 & 3,027.25 \\ \text { Log-likelihood } & -21,910.83 & -21,903.60 & -21,888.18 \\ \text { AIC } & 43,825.66 & 43,819.20 & 43,802.36 \\ \text { BIC } & 43,837.18 & 43,853.75 & 43,877.23 \\ \text { Dispersion multiplier } \alpha & 3.23^{* \star *} & 3.22^{\star *} & 3.19^{* \star *} \\ \end{array}$

${ }^{*} p<0.050{ }^{* *} p<0.010,{ }^{* * *} p<0.001$ two-sided

Discussion

This study set out to achieve a better understanding of long crime trips. In particular, its aim was to assess the influence of environmental characteristics on the incremental costs of long burglary trips. The rational choice framework was adopted and choices relating to burglary behaviour and the journey to crime were framed in terms of profit maximization and effort minimization. It was theorized that burglars have certain incentives to undertake long crime trips and that they deploy compensation strategies to make up for the incremental travel costs. We did not focus on actual burglary profits, since the exact amount and nature of such profits are unclear when a burglary is planned. Instead, we focused on how burglars anticipate these profits and identify incentives to increase their travel costs or hope to compensate for these costs. Since burglars are expected to follow a spatially structured, sequential and hierarchical target selection process in which it has been proven that environmental characteristics play an important role, it was expected that they rely on general environmental characteristics to identify incentives and form compensation strategies.

Overall, crime trip length was found to be primarily a function of the environmental characteristics of the location where the burglary occurred. Individual characteristics were of little importance. Only when community attributes were not taken into account did individual characteristics come into play. Although gender was significantly associated with crime trip length, no other individual characteristics were related to journey-to-crime distance. Moreover, the effect of gender was rendered insignificant once community characteristics were introduced into the model. In particular, the results suggest that longer crime trips were associated with burglaries committed in communities that are crossed by a motorway, contain a dense road network and have a high degree of ethnic heterogeneity. Conversely, shorter crime trips were associated with carrying out burglaries in communities with a high population density and a high burglary clearance rate. In short, burglars seemed to rely primarily on environmental characteristics to assess whether travelling costs could be increased, and whether travelling further could turn out to be more profitable.

Although individual characteristics served as control variables and were not of primary interest for our study, it should be pointed out that the current study's result do not corroborate results from earlier studies that assessed the influence of individual characteristics on the journey-to-crime distance. Briefly, the findings of our study do not provide additional support for previous research that concluded that adult burglars travel further than younger ones (Gabor \& Gottheil, 1984; Nichols, 1980; Phillips, 1980; Snook, 2004), that experienced burglars undertake longer crime trips than inexperienced burglars (Rhodes \& Conly, 1981; Van Daele \& Vander Beken, 2011b; Van Koppen \& Jansen, 1998) and that co-offending results in longer burglary trips (Levine \& Lee, 2013, p. 168; Van Daele \& Vander Beken, 2011b). Moreover, it challenges previous research (Gabor \& Gottheil, 1984, p. 276; Nichols, 1980) by finding that female burglars travelled further than male burglars. 
Next, we evaluate our hypotheses regarding environmental characteristics. First, we hypothesized that burglars prefer to operate in wealthier areas and will travel further to do so. However, the effect of property sales prices did not support this hypothesis. When controlling for individual and community characteristics, property sales prices at the community level did not increase or decrease journey-to-crime distance. This should not come as too much of a surprise, since previous studies in the Netherlands and Belgium were also unable to establish such an association (e.g. Bernasco, 2006; Bernasco \& Luykx, 2003; Bernasco \& Nieuwbeerta, 2005; Van Daele \& Vander Beken, 2011b). Although this result demonstrates that the wealth of the target area is clearly not the primary driving force behind longer crime trips, it does not in itself challenge the commonly held view that burglars are primarily driven by monetary gains since we purposively did not include measures of actual financial profits accrued. This finding suggests, however, that other community attributes are more important when balancing the costs and benefits of a burglary trip. A possible explanation for this result is that burglars expect to make a profit anyway, regardless of their economic appraisal of the target area. Offender interviews and experiments have previously demonstrated that, irrespective of the selected criminogenic environment, burglars scrutinize potential targets closely for signs of relative wealth, such as the size of the house and the presence of expensive items (e.g. Nee \& Meenaghan, 2006; Nee \& Taylor, 1988; 2000; Wright \& Logie, 1988). Thus it seems that burglars do not make an initial assessment of the wealth of a target area, but instead are guided by existing environmental wealth cues relative to a particular place and time once an area has been selected (Nee \& Taylor, 2000, p. 48; Rengert \& Wasilchick, 1985). Although this supposition could not be validated based on this study, it is likely that adopting a discrete spatial choice approach (e.g. Bernasco \& Nieuwbeerta, 2003) in which affluence measures at the community, neighbourhood and house level are included would provide evidence for its existence, or otherwise.

Second, although we expected burglars to prefer to operate in areas with a greater supply of suitable targets and to be more willing to increase the length of their crime trip to reach such areas, the effect of population density suggests otherwise. In contrast to the hypothesis, committing burglaries in densely populated areas is associated with shorter crime trips. In other words, burglars were found to be less likely to undertake longer crime trips when targeting densely populated communities. While this finding conflicts with our initial hypothesis, it is perhaps not surprising. After all, if plenty of opportunities are available close to the offender's home, why would burglars travel further afield and increase their travel costs? It seems, therefore, that an abundance of criminal opportunities in a target area is not an incentive to undertake long crime trips, when other individual and community characteristics are controlled for.

Third, our hypotheses with regard to the accessibility of target areas have been confirmed. The effects of the presence of a motorway and road density are in line with the initially formulated hypotheses, providing support for the idea that burglars compensate for increased travel costs by targeting easily accessible communities. In particular, we found that burglars were more likely to travel further to burgle in communities crossed by a motorway. Moreover, burglars targeting areas with a dense road network were more likely to travel further as well. These results are in line with those of previous journey-to-crime studies in Belgium and Canada. These studies found that burglars reduced travel time by choosing speedier travel routes when targeting areas that were further away (Beavon et al., 1994; Van Daele \& Vander Beken, 2011b). Furthermore, burglars seem to mitigate travel costs by choosing easily accessible targets (Buck, Hakim \& Rengert, 1993; Hakim, Rengert \& 
Shachmurove, 2001). The rationale behind this choice is that there are more routes leading away from the target, facilitating an easy escape and reducing the chance of being apprehended.

Finally, the estimated effects for measures of the risk of detection and arrest were mixed. In line with the hypothesis, we found that burglars undertook longer crime trips when carrying out burglaries in areas with a high degree of ethnic heterogeneity, suggesting that burglars expect increased travel costs to be compensated for by targeting areas with a lower risk of detection. Moreover, the burglary clearance rate was negatively associated with the crime trip length, suggesting that a higher chance of arrest in the target area makes burglars less likely to travel further to burgle in that area. Contrary to earlier Belgian research (Van Daele \& Vander Beken, 2011b, p. 75), we found that residential burglars appeared to be able to accurately assess actual chances of arrest Thus, burglars seem to limit travel costs when costs related to detection and arrest have already been increased. In contrast to our hypothesis, however, a community's residential mobility was not significantly related to journey-to-crime length. Similarly, Bernasco and Luykx (2003) found that burglars from The Hague in the Netherlands preferred to operate in areas with low social cohesion and little collective efficacy. It seems that burglars expect that a lack of social cohesion and collective efficacy results in a reduced risk of apprehension, and they are willing to increase their travel costs in these circumstances.

This study has several potential limitations. First, by drawing on recorded crime data the actual number of long crime trips are underestimated. While recorded crime data is the preferred data source for journey-to-crime studies (Bruinsma, 2007, p. 485), results from a recent Dutch study that used DNA traces to assess the geographical range of unidentified offenders suggest that recorded crime data might not be wholly appropriate to obtain a full understanding of the amount of mobility associated with crime (Lammers \& Bernasco, 2013). The results from this study indicate that highly mobile offenders have a reduced risk of arrest and thus a smaller chance of being present in recorded crime data. Therefore, offenders are perhaps even more mobile than has so far been reported. However, the results obtained here and in similar journey-to-crime studies should not be discarded but could be interpreted as an indication of the lower bound of the total amount of highly mobile offenders present. Regardless, it should be noted that the current study's results clearly suggest that considerable travelling is associated with burglary. Our results indicate that burglars are perhaps more mobile and crime trips are longer than has so far been reported in journey-to-crime studies. Moreover, this finding is not isolated, and ties in with the findings of other studies on the subject (e.g. Gabor \& Gottheil, 1984, p. 277; Morselli \& Royer, 2008; Rattner \& Portnov, 2007; Van Koppen \& Jansen, 1998; Wiles \& Costello, 2000).

Second, while we assumed that the offender's home acts as the starting point of the crime trip, there are doubts surrounding the validity of this claim (cf. inter alia Bruinsma, 2007, p. 485; Rossmo, 2000, p. 91). In fact, crime trips could start from a variety of locations, such as a partner's house or a pub (Wiles \& Costello, 2000). Notwithstanding the ongoing discussion on the starting point, we have left this issue largely untouched in our study for two reasons. First, we support the assertion that the location of an offender's home determines his use and understanding of the surrounding environment (Canter \& Larkin, 1993; Sarangi \& Youngs, 2006) and that offenders will have to return home at some point in time (Levine \& Lee, 2013, p. 153; Rengert, 2004, p. 169). Second, the police records used in the study do not include sufficient and valid information on secondary anchor points. Although we have information on secondary addresses for a number of offenders, such information 
is not readily available for the majority of identified offenders. We felt that only including offenders for which such information is available would limit the scope of our analysis too much.

In spite of these limitations, the current study has demonstrated that burglars are very mobile and do not shy away from undertaking long crime trips. Most importantly, this study has shown that crime trip length is primarily a function of environmental characteristics. It provides support for the idea that burglars deploy compensation strategies, e.g. by taking faster routes or by operating in communities with a lower risk of apprehension, when travelling greater distances. While some hypotheses cannot be confirmed, the results support the rational choice framework and suggest that environmental characteristics play an important role in the underlying process of profit maximization and effort minimization. Initially, some of the individual characteristics were significantly associated with crime trip length. Upon introducing the environmental characteristics into the model, however, individual characteristics no longer exhibited a significant relationship with crime trip length, suggesting that burglars, regardless of their individual characteristics, rely on environmental features to assess the benefits and drawbacks associated with increasing or decreasing travel distance. This corroborates one of the central tenets of the rational choice framework (Cornish \& Clarke, 1986, p. 2; 2008 , pp. 22, 38): although individual characteristics affect the criminal decision-making process to a certain extent, the characteristics of the crime and the current environment are the major determinants that shape criminal decisions.

Finally, there is scope for future research on two topics touched on in this study. First, the role affluence plays in burglars' assessment of incentives to undertake longer crime trips remains unclear. Intuitively, one would expect the affluence of the target area to be a major driving force behind increasing the costs of a burglary and travelling longer distances. However, we did not establish a substantial effect of affluence on crime trip length. This could be due to our particular measure of affluence, which was the average property value in the target community. It could also genuinely be the case that burglars do not make an initial assessment of the wealth of the target area since they rely on their experience and expect to make a profit anyway. This requires a different analytical strategy that includes measures of affluence and wealth of the target at different levels of aggregation. Whatever the case, this could be explored in future research by comparing competing measures of affluence or adopting alternative analytical strategies that allow affluence to be modelled at different levels of spatial aggregation. This brings us to our final suggestion.

Second, future studies could repeat and expand this study by including additional measures of a host of environmental characteristics and exploring their differential impact at different levels of aggregation. In the current study we included a selection of environmental characteristics at the community level. Our choice was primarily based on theoretical reasons but was to a certain degree also influenced by the availability of data. Data on environmental characteristics measured at the community level are readily available from Statistics Belgium, which is unfortunately not the case for environmental characteristics measured at smaller spatial units of aggregations. Theoretically, our decision to include certain environmental characteristics was guided by the outcome of previous studies. A more data-driven approach could perhaps help to identify other relevant environmental characteristics. Our decision to focus on the community level is rooted in the spatially structured, sequential and hierarchical target selection process of burglars. The initial moment of selecting a particular target area can be expected to be the time when burglars evaluate costs and benefits associated with their choice of target area. However, changes in situation and environment could 
force burglars continuously to (re-)balance their perceived costs and benefits, making this process less static than is implied in the current study. Moreover, the spatially structured, sequential, and hierarchical burglary target selection process implies that different levels of aggregation come into play at different moments in time. In other words, burglars will balance costs and benefits at different stages and times, during which different environmental characteristics could and probably will be relevant. Nevertheless, our study focused on why offenders decided to increase the costs associated with their burglary and undertake longer crime trips. Arguably, this decision is important initially, when selecting a particular target area, but will be less significant once a burglar arrives in the chosen area and begins to search for a suitable house to burgle. At that point in time other costs, such as the chance of detection and arrest, or benefits such as actual wealth of the target, might be more important factors.

\section{Acknowledgements}

The crime data for this paper was kindly provided by 46 local police forces in East and West Flanders and the Belgian Federal Police. We thank Wim Bernasco for the insightful discussions that helped us realize this paper. The authors thank the editor of this journal and two anonymous peer reviewers for helpful comments on a previous draft.

\section{References}

Baldwin, J., \& Bottoms, A. E. (1976). The urban criminal. London: Tavistock.

Beavon, D. J. K., Brantingham, P. L., \& Brantingham, P. J. (1994). The influence of street networks on the patterning of propery offenses. In R. V. Clarke (Ed.), Crime prevention studies (pp. 115148). Monsey, N.Y.: Willow Tree Press.

Bennett, T., \& Wright, R. (1984a). Burglars on burglary. Aldershot: Gower.

Bennett, T., \& Wright, R. (1984b). Constraints to burglary: The offender's perspective. In R. V. Clarke \& T. Hope (Eds.), Coping with burglary: Research perspectives on policy (pp. 181-200). Boston: Kluwer-Nijhoff.

Bernasco, W. (2006). Co-offending and the choice of target areas in burglary. Journal of Investigative Psychology and Offender Profiling, 3(3), 139-155.

Bernasco, W., \& Block, R. (2009). Where offenders choose to attack: A discrete choice model of robberies in chicago. Criminology, 47(1), 93-130.

Bernasco, W., \& Luykx, F. (2003). Effects of attractiveness, opportunity and accesibility to burglars on residential burglary rates of urban neighborhoods. Criminology, 41(3), 981-1002.

Bernasco, W., \& Nieuwbeerta, P. (2003). Hoe kiezen inbrekers een pleegbuurt? Een nieuwe benadering voor de studie van criminele doelwitselectie. Tijdschrift voor Criminologie, 45(3), 254-270.

Bernasco, W., \& Nieuwbeerta, P. (2005). How do residential burglars select target areas? A new approach to the analysis of criminal location choice. British Journal of Criminology, 45(3), 296-315.

Bichler, G., Orosco, C. A., \& Schwartz, J. A. (2012). Take the car keys away: Metropolitan structure and the long road to delinquency. Journal of Criminal Justice, 40(1), 83.

Brantingham, P. J., \& Brantingham, P. L. (1984). Patterns in crime. New York: Macmillan.

Brantingham, P. J., \& Jeffery, R. (1981). Afterword: Crime, space, and criminological theory. In P. J. Brantingham \& P. L. Brantingham (Eds.), Environmental crime (pp. 227-237). Beverly Hills: Sage.

Bruinsma, G. (2007). Urbanization and urban crime: Dutch geographical and environmental research. In M. Tonry (Ed.), Crime and justice in the netherlands (Vol. 35, pp. 453-502). Chicago: Chicago University Press. 
Buck, A. J., Hakim, S., \& Rengert, G. F. (1993). Burglar alarms and the choice behavior of burglars: A suburban phenomenon. Journal of Criminal Justice, 21(5), 497-507.

Bursik, R. J., \& Grasmick, H. G. (1993). Neighborhoods and crime. New York: Lexington Books.

Canter, D., \& Larkin, P. (1993). The environmental range of serial rapists. Journal of Environmental Psychology, 13(1), 63-69.

Canter, D., \& Youngs, D. (2008). Geographical offender profiling: Origins and principles. In D. Canter \& D. Youngs (Eds.), Principles of geographical offender profiling (pp. 1-18). Aldershot: Ashgate.

Capone, D., \& Nichols, W. (1976). Urban structure and criminal mobility. American Behavioral Scientist, 20(2), 199-213.

Chainey, S., Tompson, L., \& Uhlig, S. (2008). The utility of hotspot mapping for predicting spatial patterns of crime. Security Journal, 21(1-2), 4-28.

Cornish, D. B., \& Clarke, R. V. (1986). Introduction. In D. B. Cornish \& R. V. Clarke (Eds.), The reasoning criminal: Rational choice perspectives on offending (pp. 1-16). New York: Springer-Verlag.

Cornish, D. B., \& Clarke, R. V. (2008). The rational choice perspective. In R. Wortley \& L. Mazerolle (Eds.), Environmental criminology and crime analysis (pp. 21-47). Cullompton: Willan publishing.

Costello, A., \& Wiles, P. (2001). Gis and the journey to crime: An analysis of patterns in south yorkshire. In A. Hirschfield \& K. Bowers (Eds.), Mapping and analysing crime data: Lessons from research and practice (pp. 27-60). London: Taylor \& Francis.

Elffers, H. (2004). Decision models underlying the journey to crime. In G. Bruinsma, H. Elffers \& J. De Keijser (Eds.), Punishment, places and perpetrators: Developments in criminology and criminal justice research (pp. 182-195). Cullompton: Willan Publishing.

Felson, M. (2006). Crime and nature. Thousand Oaks: Sage.

Gabor, T., \& Gottheil, E. (1984). Offender characteristics and spatial mobility - an empirical study and some policy implications. Canadian Journal of Criminology, 26(3), 267-281.

Hakim, S., Rengert, G. F., \& Shachmurove, Y. (2001). Target search of burglars: A revised economic model. Papers in Regional Science, 80(2), 121-137.

Hesseling, R. (1992). Using data on offender mobility in ecological research. Journal of Quantitative Criminology, 8(1), 95-112.

Hilbe, J. M. (2011). Negative binomial regression. Second edition (2 ed.). Cambridge: Cambridge University Press.

Lammers, M., \& Bernasco, W. (2013). Are mobile offenders less likely to be caught? The influence of the geographical dispersion of serial offenders' crime locations on their probability of arrest. European Journal of Criminology, 10(2), 168-186.

Levine, N., \& Lee, P. (2013). Journey-to-crime by gender and age group in manchester, england. In M. Leitner (Ed.), Crime modeling and mapping using geospatial technologies (pp. 145-178). Dordrecht: Springer.

Levine, N., Lord, D., \& Park, B.-J. (2010). Crimestat version 3.3 update notes: Part 2: Regression modeling. Houston, TX: Ned Levine \& Associates.

Lu, Y. (2003). Getting away with the stolen vehicle: An investigation of journey-after-crime. The Professional Geographer, 55(4), 422-433.

Lundrigan, S., \& Czarnomski, S. (2006). Spatial characteristics of serial sexual assault in new zealand. Australian and New Zealand Journal of Criminology, 39(2), 218-231.

Maguire, M., \& Bennett, T. (1982). Burglary in a dwelling: The offence, the offender and the victim. London: Heinemann.

Mclver, J. (1981). Criminal mobility: A review of empirical studies. In S. Hakim \& G. Rengert (Eds.), Crime spillover (pp. 20-47). Beverly Hills: Sage.

Morselli, C., \& Royer, M.-N. (2008). Criminal mobility and criminal achievement. Journal of Research in Crime and Delinquency, 45(1), 4-21.

Nee, C. (2003). Research on burglary at the end of the millennium: A grounded approach to understanding crime. Secur J, 16(3), 37-44. 
Nee, C., \& Meenaghan, A. (2006). Expert decision making in burglars. British Journal of Criminology, 46(5), 935-949.

Nee, C., \& Taylor, M. (1988). Residential burglary in the republic of ireland: A situational perspective. The Howard Journal of Criminal Justice, 27(2), 105-116.

Nee, C., \& Taylor, M. (2000). Examining burglars' target selection: Interview, experiment or ethnomethodology? Psychology Crime \& Law, 6(1), 45-59.

Nichols, W. (1980). Mental maps, social characteristics, and criminal mobility. In D. Georges-Abeyie \& K. Harries (Eds.), Crime: A spatial perspective (pp. 156-166). New York: Columbia University Press.

Pettiway, L. (1982). Mobility of robbery and burglary offenders: Ghetto and nonghetto spaces. Urban Affairs Quarterly, 18(2), 255-270.

Phillips, P. (1980). Characteristics and typology of the journey to crime. In D. Georges-Abeyie \& K. Harries (Eds.), Crime: A spatial perspective (pp. 167-180). New York: Columbia University Press.

Polisenska, A. V. (2008). A qualitative approach to the criminal mobility of burglars: Questioning the 'near home' hypothesis. Crime Patterns and Analysis, 1(1), 47-60.

Pyle, G., Hanten, E., Williams, P., Pearson, A., \& Doyle, G. (1974). The spatial dynamics of crime. Chicago: University of Chicago.

Rattner, A., \& Portnov, B. A. (2007). Distance decay function in criminal behavior: A case of israel. Annals of Regional Science, 41(3), 673-688.

Rengert, G. (2004). The journey to crime. In G. Bruinsma, H. Elffers \& J. De Keijser (Eds.), Punishment, places and perpetrators: Developments in criminology and criminal justice research (pp. 169181). Cullompton: Willan Publishing.

Rengert, G., Piquero, A., \& Jones, P. (1999). Distance decay reexamined. Criminology, 37(2), 427-446.

Rengert, G., \& Wasilchick, J. (1985). Suburban burglary: A time and place for everything. Springfield, IL: Thomas.

Rhodes, W. M., \& Conly, C. (1981). Crime and mobility: An empirical study. In P. J. Brantingham \& P. L. Brantingham (Eds.), Environmental criminology (pp. 167-188). Beverly Hills: Sage.

Rossmo, K. (2000). Geographic profiling. Boca Raton: CRC Press.

Sampson, R. J., \& Groves, W. B. (1989). Community structure and crime: Testing socialdisorganization theory. American Journal of Sociology, 94(4), 774-802.

Sarangi, S., \& Youngs, D. (2006). Spatial patterns of indian serial burglars with relevance to geographical profiling. Journal of Investigative Psychology and Offender Profiling, 3(2), 105115.

Silverman, B. W. (1986). Density estimation for statistics and data analysis. London: Chapman and Hall.

Smith, W., Bond, J., \& Townsley, M. (2009). Determining how journeys-to-crime vary: Measuring inter- and intra-offender crime trip distributions. In D. Weisburd, W. Bernasco \& G. Bruinsma (Eds.), Putting crime in its place: Units of analysis in geographic criminology (pp. 217-236). New York: Springer.

Snook, B. (2004). Individual differences in distance travelled by serial burglars. Journal of Investigative Psychology and Offender Profiling, 1(1), 53-66.

Taylor, M., \& Nee, C. (1988). The role of cues in simulated residential burglary: A preliminary investigation. British Journal of Criminology, 28(3), 396-401.

Van Daele, S., \& Vander Beken, T. (2011a). Out of sight, out of mind? Awareness space and mobile offenders. European Journal of Crime, Criminal Law and Criminal Justice, 19(2), 125-137.

Van Daele, S., \& Vander Beken, T. (2011b). Outbound offending: The journey to crime and crime sprees. Journal of Environmental Psychology, 31(1), 70-78.

Van Koppen, P., \& Jansen, R. (1998). The road to robbery: Travel patterns in commercial robberies. British Journal of Criminology, 38(2), 230-246.

White, C. (1932). The relations of felonies to environmental factors in indianapolis. Social Forces, 10(4), 498-509. 
Wiles, P., \& Costello, A. (2000). The 'road to nowhere': The evidence for travelling criminals. London: Home Office.

Wright, R., \& Logie, R. H. (1988). How young house burglars choose targets. The Howard Journal of Criminal Justice, 27(2), 92-104.

Zipf, G. K. (1949). Human behavior and the principle of least-effort: An introduction to human ecology. New York: Hafner Publishing Company.

\section{Appendix 1}

Table 4 Descriptive statistics for community characteristics of burglars' home and target areas

\begin{tabular}{|c|c|c|c|c|c|c|}
\hline & & $\%$ & Mean & S.D. & Min. & Max. \\
\hline \multirow{9}{*}{$\begin{array}{l}\text { Home areas } \\
(\mathrm{N}=112)\end{array}$} & Property sales price & -- & 19.58 & 5.11 & 12.59 & 52.78 \\
\hline & Population density & -- & 4.80 & 3.17 & .53 & 18.34 \\
\hline & Motorway & -- & & & & \\
\hline & Not present $(0)$ & 49.85 & -- & -- & -- & -- \\
\hline & Present (1) & 50.15 & -- & -- & -- & -- \\
\hline & Road density & -- & 4.47 & 1.37 & 2.35 & 8.74 \\
\hline & Ethnic heterogeneity & -- & 2.15 & 1.54 & .63 & 9.65 \\
\hline & Residential mobility & -- & 4.90 & .74 & 3.51 & 7.78 \\
\hline & Clearance rate & -- & 11.10 & 5.64 & .00 & 33.33 \\
\hline \multirow{9}{*}{$\begin{array}{l}\text { Target areas } \\
(\mathrm{N}=108)\end{array}$} & Property sales price & -- & 19.65 & 5.18 & 12.59 & 52.78 \\
\hline & Population density & -- & 4.84 & 3.23 & .53 & 18.34 \\
\hline & Motorway & -- & & & & \\
\hline & Not present $(0)$ & 50.93 & -- & -- & -- & -- \\
\hline & Present (1) & 49.07 & -- & -- & -- & -- \\
\hline & Road density & -- & 4.54 & 1.44 & 2.38 & 9.79 \\
\hline & Ethnic heterogeneity & -- & 2.16 & 1.54 & .81 & 9.65 \\
\hline & Residential mobility & -- & 4.87 & .69 & 3.51 & 7.50 \\
\hline & Clearance rate & -- & 11.13 & 5.75 & .00 & 33.33 \\
\hline
\end{tabular}

\section{Appendix 2}

Kernel density estimation is a non-parametric technique to estimate the probability density function of a variable. It can be used to visualize the underlying distribution of random data by estimating a continuous, smoothed line or surface that connects all individual data points and is a very suitable technique to use when visualizing crime data (Chainey, Tompson \& Uhlig, 2008). In our paper we applied a Gaussian smoothing kernel and automatically selected a bandwidth using Silverman's (1986, p. 48) rule of thumb. 